\title{
Considerations Regarding the Establishment of the Location for a Residential Building in the Project phase Based on Energy Consumption
}

\author{
Lucian Cîrstolovean
}

\begin{abstract}
In this paper we propose to present the analysis of energy consumption for heating for a building in the design phase depending on the conditions of location in the field. We analyzed 3 variants of the location of the building. Establishing the location of the location for a building according to the estimation of energy consumption in the project phase is in accordance with the requirements established in Directive 2010/31 / EU. Design decisions can also have an impact on land use, resource use and the production of waste and emissions throughout the life cycle of the building.
\end{abstract}

Keywords - buildings, consumption, energy, life cycle, nZEB

\section{INTRODUCTION}

Directiva 2010/31/UE[1] the energy performance of buildings provided that after December 31, 2018, new occupied buildings as well as buildings owned by public authorities are buildings whose energy consumption is almost equal to zero. The Directive formulates in Art. 9 conditions for the implementation of NZEB type buildings [1]; the definition of this type of building must also include objective local characteristics.

The building is characterized by very high energy performance and the reference parameter is the primary energy indicator determined by calculation. According with Law nr. 372/2005 regarding energy performance of buildings, [2]:

- the new buildings, for which the reception at the end of the construction is carried out starting with December 31, 2020, will be buildings whose energy consumption from conventional sources is almost equal to zero;

- new buildings owned/managed by public administration authorities to be received after December 31, 2018 will be buildings whose energy consumption from primary sources is almost equal to zero.

Future climate change will lead to a variation in the energy consumption of buildings. The buildings designed according nZEB criteria today, in the future, will be less interesting. Looking at future scenarios, the annual energy performance of buildings will be changing, the energy consumption assessed today will be higher than in 2050 due mainly to the average temperature increase with $3.4-3.9^{\circ} \mathrm{C}[3]$.

The energy consumption for cooling will increase by $47.8 \%$ to $50.3 \%$, the energy consumption for heating will decrease by $129.5 \%$ and $185.8 \%$ [3], [4]. Among the 
strategies to reduce the impact of climate change is decarbonization electricity, mean reducing carbon dioxide emissions by using low-carbon energy sources, resulting an lower greenhouse gas production in the atmosphere. The effect of reducing carbon dioxide production has an impact on the life cycle of buildings, when they are dependent on electricity as the main energy source [5].

Life cycle assessment of buildings cannot determine the effect of lowering emission factors for electricity generation, as only static values are taken into account. In [5], F. Asdrubali et all proposes a dynamic assessment of the life cycle of a building to assess the consequences of reducing carbon dioxide emissions on the life cycle of a building "almost electric" energy almost zero (NZEB). As stated above, Directive 2010/31/EU [1] energy performance of buildings requires EU states to increase the number of nZEBs and rehabilitate existing buildings. Cost analyzes have been promoted to assess the economic effectiveness of building modernization interventions. Thus, the energy and carbon recovery indicator is proposed [6].

The modernization activity of the buildings involves the variation of the thickness of the insulation of construction elements, the modernization of the heat generation sources, the lighting systems, and the shading and control devices. In all cases, the energy consumption of the building is calculated and compared with the results from actual energy bills.

The difference between the final energy designed and energy monitored in operation may be due to different assumptions made during the calculations, for example, assumptions about external conditions or about the performance of installed systems or the behavior of people.

The difficulty in predicting the behavior of the residential building is a general problem. In fact, it is impossible to predict the total energy consumption with an accuracy better than $\pm 15-20 \%$, if the behavior of the inhabitants of a building is unknown.

The calculation of energy consumption may lead to larger differences compared to the monitored values, comparative with different calculation and simulation methods. If we proceed to an analysis of the Life Cycle Analysis (LCA) to determine the carbon recovery times we would get that the modernization of NZEB produces shorter energy and carbon recovery times than the life cycle of the building [6], [7], [8], [9], [10].

Below, in this paper we analized the energy consumption for heating for a building in the design phase depending on the conditions of location in the field. The design activity in the field of buildings has a major importance in establishing their energy performance.

Decisions made at the design stage regarding the shape of the building, the building materials used, the interior conformation, the orientation of the building, the size of the windows and their location will lead to a final energy demand for heating, cooling and low ventilation. Design decisions can also have an impact on land use, resource use and the production of waste and emissions throughout the life cycle of the building.

\section{EXPERIMENT DESCRIPTION}

Construction elements by definition separate the conditioned and unconditioned areas of a building or otherwise separate the indoor environment from the outdoor environment.

Heat losses through building elements can be reduced by designing buildings with a smaller thermal surface. The ratio between the surface area of the building elements and the volume of a building is called the form factor of the building. 
Buildings with larger form factors are less compact and therefore have larger areas in relation to their volume.

Different building shapes in the design stage result in different shape factors for a given volume. The smallest form factor can be obtained by a sphere, but this is not an ordinary form of building.

The relationship between the form factor and the specific final energy demand of the building is explained by the example illustrated in Figure 1.

Apartment buildings type "E" and "F" are assumed to have similar thermal characteristics, equal usable areas on each floor, heights on equal floor, number of equal levels and equal volumes.

Due to the equal volumes of the buildings, we can have equal heat losses through ventilation. Due to the equal surfaces, we can assume that for an equal number of apartments, for the same number of occupants we have an equal consumption of energy for hot water preparation and electricity.

Analyzing the building " $F$ " we have a higher value of the thermal surface for the same volume, respectively a higher form factor.

The thermal surface being higher, the heat losses in the cold period are higher. Therefore, the " $F$ " building will have a higher specific energy requirement.
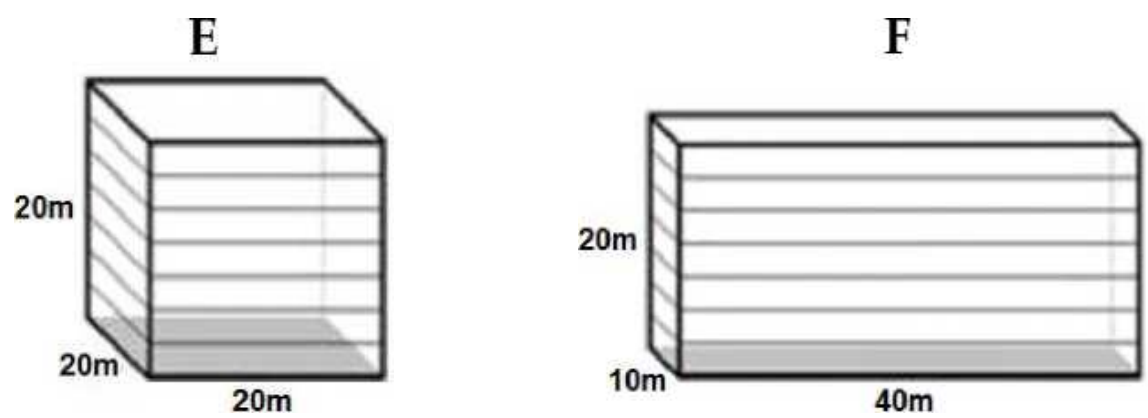

Fig.1. Form factor concept

Next we want to present the result of the studies performed: the variation of the heat demand for heating considering three variants of positioning on the site of a given building compared to a set of buildings, namely:

a) the first variant in which the given building is considered to be constituted as a building that is not part of a group of buildings, respectively it is an independent building, with four external walls;

b) the second variant in which the given building is considered as part of a set of buildings, being located at the end of this set, respectively is a building / living space with three exterior walls;

c) the third variant in which the given building is considered as part of an ensemble of buildings, being located in the middle of this ensemble, respectively it is a building / living space with two exterior walls.

The calculus was made using Methodology MC 001-1,2,3 -2009 and regulation C107/1-5/2005.The analized building is a residential building $\mathrm{P}+\mathrm{E}$ and according with regulation C 107/3-2005 ANEXA D is located in climate zone IV. The building is $\mathrm{P}+\mathrm{E}$ with identic 7 apartments on the floor. 


\section{RESULTS AND SIGNIFICANCES}

a) The calculus of necessary heat load for heating to analized building with 4 external walls [11]:

$Q_{h}=Q_{L}-\eta Q_{g},[\mathrm{kWh} / \mathrm{an}]$

$Q_{h}=$ Necessary heat load, [kWh/an], 13.977,74 [kWh/an];

$Q_{L}=$ Heat losses of building ( transmission and ventilation ), [kWh/an];

$Q_{L}=19.952,14[\mathrm{kWh} / \mathrm{an}] ;$

$Q_{g}=$ Heat load from inputs, [kWh/an], 5.974,40 [kWh/an];

$\eta=1$, using factor ( heating system operate continuu).

b) The calculus of necessary heat load for heating to analized building with 3external walls [11]:

According with equation (1) we obtain:

$Q_{h}=$ Necessary heat load, [kWh/an], 12.117,57 [kWh/an];

$Q_{L}=$ Heat losses of building (transmission and ventilation), [kWh/an];

$Q_{L}=17.916,25[\mathrm{kWh} / \mathrm{an}]$;

$Q_{g}=$ Heat load from inputs, [kWh/an], 5.798,68 [kWh/an];

$\eta=1$, using factor ( heating system operate continuu).

c) The calculus of necessary heat load for heating to analized building with 2 external walls [11]:

According with equation (1) we obtain:

$Q_{h}=$ Necessary heat load, [kWh/an], 10.343,18 [kWh/an];

$Q_{L}=$ Heat losses of building ( transmission and ventilation ), [kWh/an];

$Q_{L}=15.900,25$ [kWh/an];

$Q_{g}=$ Heat load from inputs, [kWh/an], 5.557,07 [kWh/an].

$\eta=1$, using factor ( heating system operate continuu).

\section{CONCLUSION}

1. The specific annual consumption for space heating is directly influenced by the heat demand obtained from the calculations for each variant analyzed.

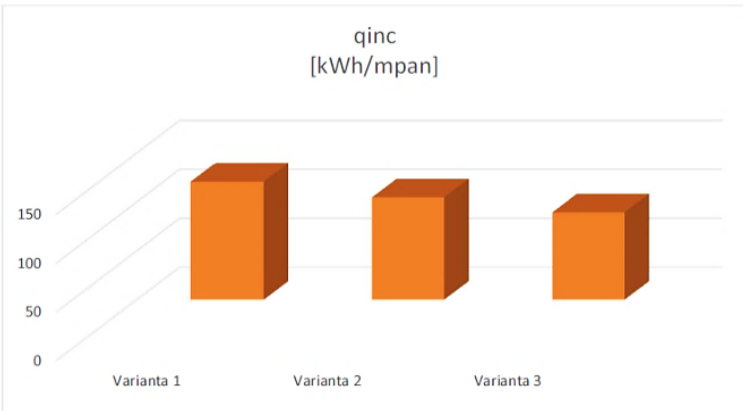

Fig 2. Variation of annual specific consumption for heating $q_{i n c}$ 
The specific annual consumption for space heating is directly influenced by the heat demand obtained from the calculations for each variant analyzed. It can be seen that, with the change of the areas of the elements of the building elements, from a building with 4 externals walls up to 3 and finally 2 external walls, change significant specific annual consumption for space heating. So, as much as the area of the external walls is smaller due to the attachment of the building with other existing buildings the specific annual consumption for heating will decrease.

2. The heat loss coefficient has the lowest value in the version with 2 exterior walls

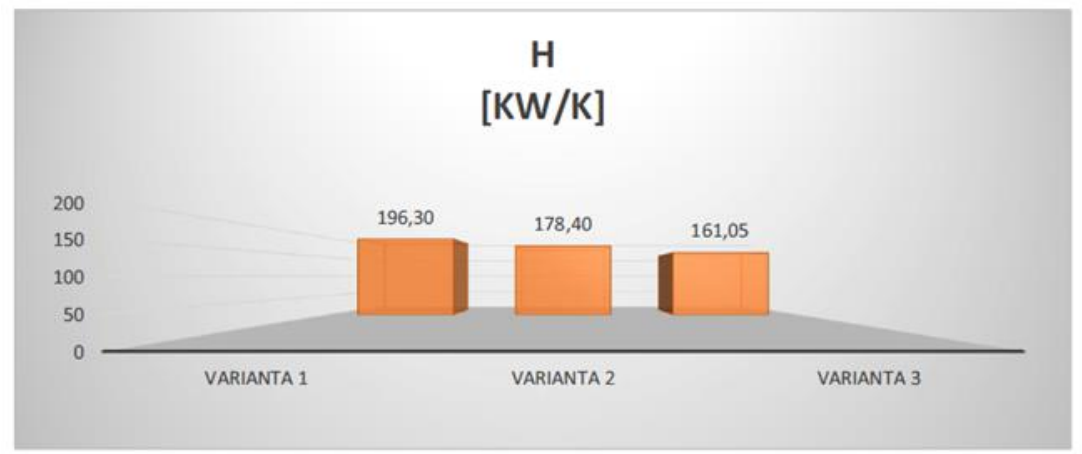

Fig 3. The variation of Coefficient $\mathrm{H}$ of heat losses in our three variants

3. The total energy consumption of a residential building depends on its location in relation to other buildings as presented above but also on the behavior of those who live in it. Performing such a calculation can lead to larger differences compared to the values monitored in operation.

4. For a low energy consumption, the design of apartments in groups of buildings with two external walls is an economical solution.

\section{REFERENCES}

[1] https://ec.europa.eu/energy/topics/energy-efficiency/energy-efficient-buildings/nearlyzero-energy-buildings_

[2] Law nr. 372/2005 Energy performance of buildings

[3] Summa S, Tarabelli L, Ulpiani G, Di Perna C. Impact of Climate Change on the Energy and Comfort Performance of nZEB: A Case Study in Italy. Climate 2020, 8(11), 125; https://doi.org/10.3390/cli8110125

[4] Ciancio, V.; Salata, F.; Falasca, S.; Curci, G.; Golasi, I.; de Wilde, P. Energy demands of buildings in the framework of climate change: An investigation across Europe. Sustain. Cities Soc. 2020, 60, 102213. [Google Scholar] [CrossRef]

[5] F. Asdrubal, P. Baggio, A. Prada, G. Graziesch, C. Guattar, Dynamic life cycle assessment modelling of a NZEB building. Energy Volume 191, 15 January 2020, 116489. https://doi.org/10.1016/j.energy.2019.116489

[6] F. Asdrubal, I. Ballarini, V. Corrado, L. Evangelisti, G. Grazieschi, C. Guattar, Energy and environmental payback times for an NZEB retrofit. Building and EnvironmentVolume 147, January 2019, Pages 461-472. https://doi.org/10.1016/j.buildenv.2018.10.047 
[7] J. Kurnitski, A. Saari, T. Kalamees, M. Vuolle, J. Niemelä, T. Tark, Cost optimal and nearly zero ( $n Z E B)$ energy performance calculations for residential buildings with REHVA definition for nZEB national implementation. Energy Build., 43 (2011), pp. 3279-3288, 10.1016/j.enbuild.2011.08.033

[8] E. Asadi, M.G. da Silva, C.H. Antunes, L. Dias. A multi-objective optimization model for building retrofit strategies using TRNSYS simulations, GenOpt and MATLAB.Build. Environ., 56 (2012), pp. 370-378, 10.1016/J.BUILDENV.2012.04.005

[9] F. Bonakdar, A. Dodoo, L. Gustavsson, Cost-optimum analysis of building fabric renovation in a Swedish multi-story residential building. Energy Build., 84 (2014), pp. $662-$ 673, 10.1016/J.ENBUILD.2014.09.003

[10]K. Kuusk, T. Kalamees, Retrofit cost-effectiveness: Estonian apartment buildings Build. Res. Inf., 44 (2016),pp. 920934, 10.1080/09613218.2016.1103117

[11] Mc 001/1,2,3-2009 Methodology for calculating the energy performance of buildings

Note:

Lucian Cîrstolovean - Transilvania University Brasov, Romania (corresponding author to provide phone: +40722294552; e-mail: ioan.cirstolovean@unitbv.ro) 